\title{
First-principles study on the stability of intermediate compounds of $\mathrm{LiBH}_{4}$
}

\author{
Nobuko Ohba, Kazutoshi Miwa, Masakazu Aoki, Tatsuo Noritake, and Shin-ichi Towata \\ Toyota Central Research \& Development Laboratories, Inc., Nagakute, Aichi 480-1192, Japan \\ Yuko Nakamori and Shin-ichi Orimo \\ Institute for Materials Research, Tohoku University, Sendai 980-8577, Japan \\ Andreas Züttel \\ Physics Department, University of Fribourg, Perolles, CH-1700 Fribourg, Switzerland \\ and Department of Environment, Energy and Mobility, EMPA, Dübendorf 8600, Switzerland \\ (Received 20 January 2006; revised manuscript received 20 April 2006; published 25 August 2006)
}

\begin{abstract}
We report the results of the first-principles calculation on the intermediate compounds of $\mathrm{LiBH}_{4}$. The stability of $\mathrm{LiB}_{3} \mathrm{H}_{8}$ and $\mathrm{Li}_{2} \mathrm{~B}_{n} \mathrm{H}_{n}(n=5-12)$ has been examined with the ultrasoft pseudopotential method based on the density-functional theory. Theoretical prediction has suggested that monoclinic $\mathrm{Li}_{2} \mathrm{~B}_{12} \mathrm{H}_{12}$ is the most stable among the candidate materials. We propose the following hydriding (dehydriding) process of $\mathrm{LiBH}_{4}$ via this intermediate compound: $\mathrm{LiBH}_{4} \leftrightarrow \frac{1}{12} \mathrm{Li}_{2} \mathrm{~B}_{12} \mathrm{H}_{12}+\frac{5}{6} \mathrm{LiH}+\frac{13}{12} \mathrm{H}_{2} \leftrightarrow \mathrm{LiH}+\mathrm{B}+\frac{3}{2} \mathrm{H}_{2}$. The hydrogen content and enthalpy of the first reaction are estimated to be 10 mass $\%$ and $56 \mathrm{~kJ} / \mathrm{mol} \mathrm{H}_{2}$, respectively, and those of the second reaction are 4 mass $\%$ and $125 \mathrm{~kJ} / \mathrm{mol} \mathrm{H}_{2}$. They are in good agreement with experimental results of the thermal desorption spectra of $\mathrm{LiBH}_{4}$. Our calculation has predicted that the bending modes for the $\Gamma$-phonon frequencies of monoclinic $\mathrm{Li}_{2} \mathrm{~B}_{12} \mathrm{H}_{12}$ are lower than that of $\mathrm{LiBH}_{4}$, while stretching modes are higher. These results are very useful for the experimental search and identification of possible intermediate compounds.
\end{abstract}

DOI: 10.1103/PhysRevB.74.075110

PACS number(s): 71.20.Ps, 61.66.Fn, 63.20.Dj, 71.15.Mb

\section{INTRODUCTION}

Hydrogen is the most promising environmentally clean energy carrier to replace fossil fuels. The use of hydrogenbased energy in practical applications such as fuel cell vehicles, however, requires the development of safe and efficient hydrogen storage technology. Complex hydrides, including the light metal lithium $(\mathrm{Li})$, have sufficient gravimetric hydrogen storage capacity, and a great amount of research and development about lithium complex hydrides, such as $\mathrm{LiBH}_{4}$ (Refs. 1-3) and $\mathrm{LiNH}_{2}$ (Refs. 4-6) has been done recently. Particularly, $\mathrm{LiBH}_{4}$ can desorb about 14 mass $\%$ of hydrogen by the following thermal decomposition:

$$
\mathrm{LiBH}_{4} \rightarrow \mathrm{LiH}+\mathrm{B}+\frac{3}{2} \mathrm{H}_{2} .
$$

However, the experimental value of enthalpy of this reaction is $69 \mathrm{~kJ} / \mathrm{mol} \mathrm{H}_{2}$ (Ref. 1), and $\mathrm{LiBH}_{4}$ is too stable to release hydrogen at ambient condition. High temperature and high pressure are needed for a rehydriding reaction, so its reversibility becomes a problem for practical use.

Züttel et al. ${ }^{1}$ investigated the hydrogen desorption from $\mathrm{LiBH}_{4}$ in detail, and reported that the thermal-desorption spectra of $\mathrm{LiBH}_{4}$ mixed with $\mathrm{SiO}_{2}$ powder exhibited three hydrogen desorption peaks. These peaks were observed around 500, 550, and $600 \mathrm{~K}$, and the products corresponded to " $\mathrm{LiBH}_{3.6}$," " $\mathrm{LiBH}_{3}$," and " $\mathrm{LiBH}_{2}$," respectively. The compounds in quotes were nominal compositions estimated from the amount of desorbed hydrogen. This is strong evidence for the existence of the intermediate compound, and the hydrogen desorption reaction takes place in at least two steps, not a single step such as in Eq. (1). Although the low- temperature release of hydrogen and the improvement of reversibility can be expected by the use of the intermediate compound, this has received little attention.

In this study, the stability of the intermediate compounds of $\mathrm{LiBH}_{4}$ has been investigated theoretically and we clarify a hydriding (dehydriding) process of $\mathrm{LiBH}_{4}$. The thermal desorption experiment observed a structural transition around $380 \mathrm{~K}$ and the melting of the compound at $550 \mathrm{~K}$. The stability of the solid phases at absolute zero temperature is mainly discussed here. In Sec. II, we describe the details of the computational method and the possible intermediate compounds of $\mathrm{LiBH}_{4}$. Section III reports the calculated results on the stability of some candidate compounds. Then, we discuss the hydriding (dehydriding) reaction via the intermediate compounds. Furthermore, the electronic structures and $\Gamma$-phonon frequencies on the most stable compound are studied. We also investigate the stability of the borane complex anions, and then compare our results with the solid compounds.

\section{COMPUTATIONAL DETAILS}

First-principles calculations have been performed by the ultrasoft pseudopotential method ${ }^{7}$ based on the densityfunctional theory. ${ }^{8}$ The generalized-gradient-approximation (GGA) formula ${ }^{9}$ is applied to the exchange-correlation energy.

The interaction between the ion cores and electrons is described by the ultrasoft pseudopotential, ${ }^{7}$ and the normconservation constraint ${ }^{10}$ is imposed on $\mathrm{Li}$ for the calculation-efficiency improvement. The scalar-relativistic all-electron calculations are first carried out on the free atoms 
(ions). We chose $2 s$ and $2 p$ states for both $\mathrm{Li}$ and B pseudopotential as the reference states with the cutoff radii of 2 a.u. (Li) and 1.5 a.u. (B), respectively. A single projector function is used for each angular-momentum component. The $3 d$ state is treated as the local part of the pseudopotential. The hydrogen pseudopotential is constructed from $1 s, 2 s$, and $2 p$ states with the cutoff radii of 1.1 a.u. $(s)$ and 1.2 a.u. $(p)$. We use double projector functions for the $s$ component and a single projector function for the $p$ component. For all pseudopotentials, the pseudowave functions and the pseudochargeaugmentation functions are optimized by a method similar to that proposed by Rappe et al. ${ }^{11}$ Also, the partial core correction ${ }^{12}$ is taken into account for $\mathrm{Li}$ and $\mathrm{B}$ pseudopotentials.

In the solid-state calculations, the pseudowave functions are expanded by plane waves with a cutoff energy equal to 15 hartrees. The cutoff energy for the charge density and potential is set to be 120 hartrees. The integral over the Brillouin zone is approximated by the summation on the $\mathbf{k}$-grid elements of which the edge lengths will be as close to the target value of $0.15 \AA^{-1}$ as possible. We confirmed that these calculation conditions gave a good convergence of energy within $0.002 \mathrm{eV} /$ atom. The preconditioned conjugategradient technique is employed to minimize the Kohn-Sham energy functional. A procedure based on the iterative diagonalization scheme 13 and the Broyden charge-mixing method $^{14}$ is adopted in this study. Optimization of crystal structures is performed until the atomic forces and the macroscopic stresses become less than $5 \times 10^{-4}$ hartree/bohr and $0.1 \mathrm{GPa}$, respectively. During the structural-optimization process, the partial occupation numbers near the Fermi level are determined by the Fermi-Dirac distribution function with $k_{B} T=3 \times 10^{-3}$ hartrees. The Helmholtz free-energy functional, ${ }^{15}$ including the entropy term, is minimized instead of the Kohn-Sham energy functional. Then, the improved tetrahedron method ${ }^{16}$ is used in order to minimize the Kohn-Sham energy functional in the optimized structure. The dynamical matrix is calculated by the force-constant method $^{17}$ to obtain the $\Gamma$-phonon frequencies. The atomic displacement is set to be $0.02 \AA$. The further details of calculation are described in Refs. 2 and 13, and references therein.

As the candidates of the intermediate compounds, the existing alkali-metal B-H materials are used. For example, it is well known that boron (B) and hydrogen ( $\mathrm{H})$ form inorganic compounds called "borane" and the compounds of $\mathrm{CsB}_{3} \mathrm{H}_{8}$, ${ }^{18} \mathrm{~K}_{2} \mathrm{~B}_{6} \mathrm{H}_{6},{ }^{19}$ and $\mathrm{K}_{2} \mathrm{~B}_{12} \mathrm{H}_{12}$ (Ref. 20) are reported. The space group of crystal structure for the compound $\mathrm{CsB}_{3} \mathrm{H}_{8}$ is Ama2 (No. 40) and cation $\mathrm{Cs}^{+}$and anion $\left[\mathrm{B}_{3} \mathrm{H}_{8}\right]^{-}$are arranged the same as the NaCl-type structure with an orthorhombic distortion. The crystal structures of $\mathrm{K}_{2} \mathrm{~B}_{6} \mathrm{H}_{6}$ and $\mathrm{K}_{2} \mathrm{~B}_{12} \mathrm{H}_{12}$ are best described as an anti-CaF $\mathrm{F}_{2}$-type arrangement with $\mathrm{K}^{+}$cation in the center of a tetrahedron formed by $\left[\mathrm{B}_{n} \mathrm{H}_{n}\right]^{2-}$ dianions. We first assumed that $\mathrm{LiB}_{3} \mathrm{H}_{8}, \mathrm{Li}_{2} \mathrm{~B}_{6} \mathrm{H}_{6}$, and $\mathrm{Li}_{2} \mathrm{~B}_{12} \mathrm{H}_{12}$ compounds had the same crystal structures as existing $\mathrm{CsB}_{3} \mathrm{H}_{8}, \mathrm{~K}_{2} \mathrm{~B}_{6} \mathrm{H}_{6}$, and $\mathrm{K}_{2} \mathrm{~B}_{12} \mathrm{H}_{12}$, respectively. The stability of these candidates was evaluated using the firstprinciples calculations. Since the existence of a series of closo-type dianions $\left[\mathrm{B}_{n} \mathrm{H}_{n}\right]^{2-}(n=5-12)$ is also well known, our calculations have been expanded to $\mathrm{Li}_{2} \mathrm{~B}_{n} \mathrm{H}_{n}(n=5-12)$ compounds. Although the $\mathrm{Li}$ atom and $\left[\mathrm{B}_{n} \mathrm{H}_{n}\right]$ cluster are arranged in the anti-CaF $-\mathrm{C}_{2}$-type structure and the unit-cell parameters are supposed to be a face-centered-cubic symmetry $\left(a=b=c, \alpha=\beta=\delta=90^{\circ}\right)$ as starting points for the structural optimization, the output relaxed compounds have different symmetry depending on the structure of $\left[\mathrm{B}_{n} \mathrm{H}_{n}\right]$ clusters. The alkali-metal salt of monoclinic $\mathrm{K}_{2} \mathrm{~B}_{12}(\mathrm{OH})_{12}$ (Ref. 21) with closo- $\left[\mathrm{B}_{12}(\mathrm{OH})_{12}\right]^{2-}$ dianions has been reported, and monoclinic $\mathrm{Li}_{2} \mathrm{~B}_{12} \mathrm{H}_{12}$ with similar crystal structure is also examined.

\section{RESULTS AND DISCUSSIONS}

\section{A. Stability of candidate compounds: $\mathrm{LiB}_{x} \mathrm{H}_{y}$}

Table I shows the calculated results on the structural parameters and the cohesive energies of $\mathrm{LiB}_{3} \mathrm{H}_{8}$ and $\mathrm{Li}_{2} \mathrm{~B}_{n} \mathrm{H}_{n}(n=5-12)$. We denote the cubic $\mathrm{Li}_{2} \mathrm{~B}_{12} \mathrm{H}_{12}$ based on $\mathrm{K}_{2} \mathrm{~B}_{12} \mathrm{H}_{12}$ with type 1 and monoclinic $\mathrm{Li}_{2} \mathrm{~B}_{12} \mathrm{H}_{12}$ based on $\mathrm{K}_{2} \mathrm{~B}_{12}(\mathrm{OH})_{12}$ with type 2 , respectively. Compared with the cohesive energy of two type of $\mathrm{Li}_{2} \mathrm{~B}_{12} \mathrm{H}_{12}$, the value of monoclinic $\mathrm{Li}_{2} \mathrm{~B}_{12} \mathrm{H}_{12}$ (type 2) is larger than that of type 1 . Therefore, the type $2 \mathrm{Li}_{2} \mathrm{~B}_{12} \mathrm{H}_{12}$ is easy to form. After the next paragraph, the only result concerning monoclinic $\mathrm{Li}_{2} \mathrm{~B}_{12} \mathrm{H}_{12}$ (type 2) is shown.

The enthalpy of formation for hydriding reactions including $\mathrm{LiBH}_{4}$ from $\mathrm{LiH}$ (NaCl-type), $\alpha$-B (rhombohedral), and $\mathrm{H}_{2}$ molecule are given in Table II, where the zero-point energy corrections are not taken into consideration. They are provided using calculated cohesive energies of $2.3609 \mathrm{eV} /$ atom for $\mathrm{LiH}, 6.2013 \mathrm{eV} /$ atom for $\alpha-\mathrm{B}$, $2.2689 \mathrm{eV} /$ atom for $\mathrm{H}_{2}$ molecule, and $3.1501 \mathrm{eV} /$ atom for $\mathrm{LiBH}_{4}$ (orthorhombic Pnma symmetry), respectively. The enthalpies of formation for $\mathrm{Li}_{2} \mathrm{~B}_{n} \mathrm{H}_{n}(n=10-12)$ are more negative than that for $\mathrm{LiBH}_{4}$. Therefore these compounds have a great potential for generating in hydriding reactions from $\mathrm{LiH}$ and $\alpha$-B as the intermediate phase of $\mathrm{LiBH}_{4}$.

In order to understand the relative stability of each compound for $\mathrm{LiBH}_{4}$ intuitively, we investigate the relation between the formation enthalpy and the mole fraction of $\mathrm{H}_{2}$. The enthalpy of formation corresponding to the following reaction with hydrogen of $\delta$ mole is plotted in Fig. 1:

$$
(1-\delta)[\mathrm{LiH}+\mathrm{B}]+\delta \mathrm{H}_{2} \rightarrow \frac{1-\delta}{x} \mathrm{LiB}_{x} \mathrm{H}_{y}+\frac{(1-\delta)(x-1)}{x} \mathrm{LiH}
$$

where $\delta=(y-1) /(2 x+y-1)$ and $x \geqslant 1$. This type of figure, such as Fig. 1, is often used in discussing the stability of multiphases such as the alloy system. Assuming the lines that connect each point and the origin $(0,0)$ or $(1,0)$ or another point, we can evaluate the enthalpy of the reaction when the $(1-\delta)$ mole of $[\mathrm{LiH}+\mathrm{B}]$ and the $\delta$ mole of $\mathrm{H}_{2}$ react and compounds $\mathrm{LiB}_{x} \mathrm{H}_{y}$ are produced. From Fig. 1, monoclinic $\mathrm{Li}_{2} \mathrm{~B}_{12} \mathrm{H}_{12}$ is formed as the intermediate compound of the hydriding (dehydriding) reaction of $\mathrm{LiBH}_{4}$, because the actual reaction goes along the lowest state of enthalpy. Therefore, the following hydriding (dehydriding) process is proposed: 
TABLE I. Structural parameters and cohesive energies $\left(E_{c o h}\right)$ of the candidate compounds: $\mathrm{LiB}_{x} \mathrm{H}_{y}$. It is denoted that the cubic $\mathrm{Li}_{2} \mathrm{~B}_{12} \mathrm{H}_{12}$ is based on $\mathrm{K}_{2} \mathrm{~B}_{12} \mathrm{H}_{12}$ with type 1 and the monoclinic $\mathrm{Li}_{2} \mathrm{~B}_{12} \mathrm{H}_{12}$ is based on $\mathrm{K}_{2} \mathrm{~B}_{12}(\mathrm{OH})_{12}$ with type 2 , respectively.

\begin{tabular}{|c|c|c|c|c|c|c|c|c|}
\hline \multirow[b]{2}{*}{ Compound } & \multirow[b]{2}{*}{ Space group } & \multirow[b]{2}{*}{ Unit cell parameters } & \multicolumn{5}{|c|}{ Atomic position } & \multirow{2}{*}{$\begin{array}{c}E_{c o h} \\
\text { (eV/atom) }\end{array}$} \\
\hline & & & Atom & Site & $x / a$ & $y / b$ & $z / c$ & \\
\hline \multirow[t]{8}{*}{$\mathrm{LiB}_{3} \mathrm{H}_{8}$} & Ama2 & $a=9.188 \AA$ & $\mathrm{Li}$ & $4 b$ & 0.0595 & 0.6321 & 0.25 & 3.3770 \\
\hline & (No. 40) & $b=8.813 \AA$ & B1 & $4 b$ & 0.1372 & 0.1335 & 0.25 & \\
\hline & & $c=5.763 \AA$ & B2 & $8 c$ & 0.3090 & 0.1331 & 0.0945 & \\
\hline & & & $\mathrm{H} 1$ & $4 b$ & 0.0690 & 0.2507 & 0.25 & \\
\hline & & & $\mathrm{H} 2$ & $4 b$ & 0.0684 & 0.1666 & 0.25 & \\
\hline & & & H3 & $8 c$ & 0.1386 & 0.5149 & 0.5190 & \\
\hline & & & $\mathrm{H} 4$ & $8 c$ & 0.1823 & 0.1333 & 0.0063 & \\
\hline & & & H5 & $8 c$ & 0.3619 & 0.2508 & 0.0186 & \\
\hline \multirow[t]{8}{*}{$\mathrm{Li}_{2} \mathrm{~B}_{5} \mathrm{H}_{5}$} & $R 3 m$ & $a=5.599 \AA$ & Li1 & $3 a$ & 0 & 0 & 0.2755 & 3.7910 \\
\hline & (No. 160) & $c=16.763 \AA$ & $\mathrm{Li} 2$ & $3 a$ & 0 & 0 & 0.7513 & \\
\hline & (hexagonal axes) & & B1 & $3 a$ & 0 & 0 & 0.0876 & \\
\hline & & & B2 & $3 a$ & 0 & 0 & 0.9295 & \\
\hline & & & B3 & $9 b$ & 0.1070 & 0.8930 & 0.0084 & \\
\hline & & & H1 & $3 a$ & 0 & 0 & 0.1595 & \\
\hline & & & $\mathrm{H} 2$ & $3 a$ & 0 & 0 & 0.8586 & \\
\hline & & & H3 & $9 b$ & 0.2270 & 0.7730 & -0.0078 & \\
\hline \multirow[t]{3}{*}{$\mathrm{Li}_{2} \mathrm{~B}_{6} \mathrm{H}_{6}$} & $F m \overline{3} m$ & $a=7.968 \AA$ & $\mathrm{Li}$ & $8 c$ & 0.25 & 0.25 & 0.25 & 4.0429 \\
\hline & (No. 225) & & B & $24 e$ & 0.1553 & 0 & 0 & \\
\hline & & & $\mathrm{H}$ & $24 e$ & 0.3054 & 0 & 0 & \\
\hline \multirow[t]{10}{*}{$\mathrm{Li}_{2} \mathrm{~B}_{7} \mathrm{H}_{7}$} & $I 2$ & $a=5.691 \AA$ & Li1 & $2 b$ & 0 & 0.1501 & 0.5 & 4.0850 \\
\hline & (No. 5) & $b=9.836 \AA$ & $\mathrm{Li} 2$ & $2 b$ & 0.5 & 0.2317 & 0 & \\
\hline & & $c=5.625 \AA$ & B1 & $2 a$ & 0 & 0.1564 & 0 & \\
\hline & & $\beta=77.39^{\circ}$ & B2 & $4 c$ & -0.1871 & 0.0529 & -0.1063 & \\
\hline & & & B3 & $4 c$ & 0.1160 & -0.1087 & 0.0659 & \\
\hline & & & B4 & $4 c$ & -0.1335 & 0.0087 & 0.1903 & \\
\hline & & & H1 & $2 a$ & 0 & 0.2792 & 0 & \\
\hline & & & $\mathrm{H} 2$ & $4 c$ & -0.3463 & 0.0805 & -0.2099 & \\
\hline & & & $\mathrm{H} 3$ & $4 c$ & 0.2215 & -0.2030 & 0.1343 & \\
\hline & & & $\mathrm{H} 4$ & $4 c$ & -0.2700 & 0.0109 & 0.3879 & \\
\hline \multirow[t]{5}{*}{$\mathrm{Li}_{2} \mathrm{~B}_{8} \mathrm{H}_{8}$} & $I \overline{4} 2 \mathrm{~m}$ & $a=5.572 \AA$ & $\mathrm{Li}$ & $4 d$ & 0 & 0.5 & 0.25 & 4.0920 \\
\hline & (No. 121) & $c=10.687 \AA$ & B1 & $8 i$ & 0.1032 & 0.1032 & -0.1242 & \\
\hline & & & B2 & $8 i$ & 0.1631 & 0.1631 & 0.0304 & \\
\hline & & & H1 & $8 i$ & 0.2031 & 0.2031 & -0.2112 & \\
\hline & & & $\mathrm{H} 2$ & $8 i$ & 0.3114 & 0.3114 & 0.0580 & \\
\hline \multirow[t]{8}{*}{$\mathrm{Li}_{2} \mathrm{~B}_{9} \mathrm{H}_{9}$} & $R 3$ & $a=7.044 \AA$ & Li1 & $3 a$ & 0 & 0 & 0.2482 & 4.1326 \\
\hline & (No. 146) & $c=15.062 \AA$ & $\mathrm{Li} 2$ & $3 a$ & 0 & 0 & 0.8070 & \\
\hline & (hexagonal axes) & & B1 & $9 b$ & 0.8087 & 0.9031 & 0.9508 & \\
\hline & & & B2 & $9 b$ & 0.8118 & 0.9047 & 0.0694 & \\
\hline & & & B3 & $9 b$ & 0.8661 & 0.7287 & 0.0096 & \\
\hline & & & H1 & $9 b$ & 0.6730 & 0.8346 & 0.8923 & \\
\hline & & & $\mathrm{H} 2$ & $9 b$ & 0.6756 & 0.8357 & 0.1281 & \\
\hline & & & H3 & $9 b$ & 0.7699 & 0.5322 & 0.0141 & \\
\hline \multirow[t]{3}{*}{$\mathrm{Li}_{2} \mathrm{~B}_{10} \mathrm{H}_{10}$} & $I 422$ & $a=6.196 \AA$ & $\mathrm{Li}$ & $4 d$ & 0 & 0.5 & 0.25 & 4.2360 \\
\hline & (No. 97) & $c=10.356 \AA$ & B1 & $4 e$ & 0 & 0 & 0.1827 & \\
\hline & & & $\mathrm{B} 2$ & $16 k$ & 0.1942 & -0.0809 & 0.0739 & \\
\hline
\end{tabular}


TABLE I. (Continued.)

\begin{tabular}{|c|c|c|c|c|c|c|c|c|}
\hline \multirow[b]{2}{*}{ Compound } & \multirow[b]{2}{*}{ Space group } & \multirow[b]{2}{*}{ Unit cell parameters } & \multicolumn{5}{|c|}{ Atomic position } & \multirow{2}{*}{$\begin{array}{c}E_{c o h} \\
\text { (eV/atom) }\end{array}$} \\
\hline & & & Atom & Site & $x / a$ & $y / b$ & $z / c$ & \\
\hline & & & H1 & $4 e$ & 0 & 0 & 0.2984 & \\
\hline & & & $\mathrm{H} 2$ & $16 k$ & 0.3647 & -0.1582 & 0.1070 & \\
\hline \multirow[t]{14}{*}{$\mathrm{Li}_{2} \mathrm{~B}_{11} \mathrm{H}_{11}$} & $I 2$ & $a=7.083 \AA$ & Li1 & $2 b$ & 0 & -0.1091 & 0.5 & 4.2397 \\
\hline & (No. 5) & $b=11.028 \AA$ & Li2 & $2 b$ & 0.5 & -0.1083 & 0 & \\
\hline & & $c=7.080 \AA$ & B1 & $2 a$ & 0 & -0.1264 & 0 & \\
\hline & & $\beta=70.52^{\circ}$ & B2 & $4 c$ & 0.1117 & 0.1190 & -0.1120 & \\
\hline & & & B3 & $4 c$ & 0.0835 & -0.0162 & -0.2427 & \\
\hline & & & B4 & $4 c$ & 0.2425 & -0.0162 & -0.0840 & \\
\hline & & & B5 & $4 c$ & 0.1293 & 0.0825 & 0.1290 & \\
\hline & & & B6 & $4 c$ & 0.1448 & -0.0795 & 0.1446 & \\
\hline & & & H1 & $2 a$ & 0 & -0.2355 & 0 & \\
\hline & & & $\mathrm{H} 2$ & $4 c$ & 0.2016 & 0.2052 & -0.2020 & \\
\hline & & & H3 & $4 c$ & 0.4160 & -0.0284 & -0.1910 & \\
\hline & & & $\mathrm{H} 4$ & $4 c$ & 0.1902 & -0.0283 & -0.4165 & \\
\hline & & & H5 & $4 c$ & 0.2133 & 0.1471 & 0.2127 & \\
\hline & & & H6 & $4 c$ & 0.2305 & -0.1441 & 0.2300 & \\
\hline \multirow{3}{*}{$\begin{array}{l}\mathrm{Li}_{2} \mathrm{~B}_{12} \mathrm{H}_{12} \\
\text { (type } 1 \text { ) }\end{array}$} & $F m \overline{3}$ & $a=10.083 \AA$ & $\mathrm{Li}$ & $8 c$ & 0.25 & 0.25 & 0.25 & 4.2997 \\
\hline & (No. 202) & & $\mathrm{B}$ & $48 h$ & 0 & 0.1448 & 0.0881 & \\
\hline & & & $\mathrm{H}$ & $48 h$ & 0 & 0.2490 & 0.1469 & \\
\hline \multirow{13}{*}{$\begin{array}{l}\mathrm{Li}_{2} \mathrm{~B}_{12} \mathrm{H}_{12} \\
\text { (type 2) }\end{array}$} & $P 2_{1} / n$ & $a=7.358 \AA$ & $\mathrm{Li}$ & $4 e$ & 0.6747 & 0.6250 & 0.5323 & 4.3461 \\
\hline & (No. 14) & $b=9.556 \AA$ & B1 & $4 e$ & 0.6770 & 0.5392 & 0.1632 & \\
\hline & & $c=6.768 \AA$ & B2 & $4 e$ & 0.4447 & 0.5629 & 0.2239 & \\
\hline & & $\beta=92.26^{\circ}$ & B3 & $4 e$ & 0.5425 & 0.6760 & 0.0442 & \\
\hline & & & B4 & $4 e$ & 0.6915 & 0.5689 & 0.9022 & \\
\hline & & & B5 & $4 e$ & 0.6856 & 0.3922 & 0.9959 & \\
\hline & & & B6 & $4 e$ & 0.5329 & 0.3887 & 0.1933 & \\
\hline & & & H1 & $4 e$ & 0.8033 & 0.5642 & 0.2786 & \\
\hline & & & $\mathrm{H} 2$ & $4 e$ & 0.4008 & 0.6050 & 0.3840 & \\
\hline & & & $\mathrm{H} 3$ & $4 e$ & 0.5707 & 0.7983 & 0.0742 & \\
\hline & & & $\mathrm{H} 4$ & $4 e$ & 0.8252 & 0.6151 & 0.8271 & \\
\hline & & & H5 & $4 e$ & 0.8231 & 0.3231 & 0.9941 & \\
\hline & & & H6 & $4 e$ & 0.5558 & 0.3097 & 0.3310 & \\
\hline
\end{tabular}

$$
\begin{aligned}
\mathrm{LiBH}_{4} & \leftrightarrow \frac{1}{12} \mathrm{Li}_{2} \mathrm{~B}_{12} \mathrm{H}_{12}+\frac{5}{6} \mathrm{LiH}+\frac{13}{12} \mathrm{H}_{2} \\
& \leftrightarrow \mathrm{LiH}+\mathrm{B}+\frac{3}{2} \mathrm{H}_{2} .
\end{aligned}
$$

The enthalpy without the zero-point energy effects and hydrogen content of the first reaction [Eq. (3)] are $56 \mathrm{~kJ} / \mathrm{mol}$ $\mathrm{H}_{2}$ and 10 mass $\%$, and those of the second reaction [Eq. (4)] are $125 \mathrm{~kJ} / \mathrm{mol} \mathrm{H}_{2}$ and 4 mass $\%$, respectively. These results agree with the experimental ones, which reported that 9 mass $\%$ of hydrogen is liberated in the hydrogen desorption peak in the thermal desorption spectra of $\mathrm{LiBH}_{4}$ mixed with $\mathrm{SiO}_{2}$-powder in Ref. 1. The enthalpy value of $56 \mathrm{~kJ} / \mathrm{mol} \mathrm{H}_{2}$ for the first reaction is lower than the computational one of $75 \mathrm{~kJ} / \mathrm{mol} \mathrm{H}_{2}$ for the direct dehydriding reaction of $\mathrm{LiBH}_{4}$ [Eq. (1)]. ${ }^{2}$ So, the hydrogen desorption and absorption can occur at low temperature and pressure com- paratively by using this intermediate compound.

We also calculated other possible crystal structures such as $\mathrm{Cu}_{2} \mathrm{~B}_{10} \mathrm{H}_{10}$-type ${ }^{22}$ and $\left[\mathrm{Li}(\text { thp })_{3}\right]_{2}\left[\mathrm{~B}_{11} \mathrm{H}_{11}\right]$-type. ${ }^{23}$ Moreover, we performed the calculation for the $\Gamma$-phonon frequencies of the candidate materials. If there was a soft mode, we lowered the crystal-structure symmetry by moving the atoms along the direction of the soft-mode eigenvectors. The maximum gain of cohesive energy was $0.03 \mathrm{eV} /$ atom for $\mathrm{Li}_{2} \mathrm{~B}_{6} \mathrm{H}_{6}$; however, no compound or crystal structure more stable than monoclinic $\mathrm{Li}_{2} \mathrm{~B}_{12} \mathrm{H}_{12}$ was found. The present calculation result on the energy of monoclinic $\mathrm{Li}_{2} \mathrm{~B}_{12} \mathrm{H}_{12}$ provides the upper-limit value for the thermodynamic stability. In conclusion, the existence of the intermediate compound of $\mathrm{LiBH}_{4}$ was predicted theoretically.

Recently, Kang et al. ${ }^{24}$ have reported that $\mathrm{LiBH}$ and $\mathrm{LiB}$ are the intermediate phases of $\mathrm{LiBH}_{4}$, and propose the dehydriding reaction of $\mathrm{LiBH}_{4}$ through $\mathrm{LiBH}$ as follows: 
TABLE II. The enthalpies of formation for the hydriding reaction of various compounds $\mathrm{LiB}_{x} \mathrm{H}_{y}$, including $\mathrm{LiBH}_{4}$ from $\mathrm{LiH}$, $\alpha$ - $\mathrm{B}$, and $\mathrm{H}_{2}$ molecule, where the zero-point energy corrections are not taken into consideration.

\begin{tabular}{cc}
\hline \hline Hydriding reaction & $\begin{array}{c}\text { Enthalpy } \\
\text { of formation } \\
(\mathrm{kJ} / \mathrm{mol} \mathrm{H})\end{array}$ \\
\hline $\mathrm{LiH}+3 \mathrm{~B}+\frac{7}{2} \mathrm{H}_{2} \rightarrow \mathrm{LiB}_{3} \mathrm{H}_{8}$ & -36 \\
$2 \mathrm{LiH}+5 \mathrm{~B}+\frac{3}{2} \mathrm{H}_{2} \rightarrow \mathrm{Li}_{2} \mathrm{~B}_{5} \mathrm{H}_{5}$ & 113 \\
$2 \mathrm{LiH}+6 \mathrm{~B}+2 \mathrm{H}_{2} \rightarrow \mathrm{Li}_{2} \mathrm{~B}_{6} \mathrm{H}_{6}$ & -42 \\
$2 \mathrm{LiH}+7 \mathrm{~B}+\frac{5}{2} \mathrm{H}_{2} \rightarrow \mathrm{Li}_{2} \mathrm{~B}_{7} \mathrm{H}_{7}$ & -45 \\
$2 \mathrm{LiH}+8 \mathrm{~B}+3 \mathrm{H}_{2} \rightarrow \mathrm{Li}_{2} \mathrm{~B}_{8} \mathrm{H}_{8}$ & -32 \\
$2 \mathrm{LiH}+9 \mathrm{~B}+\frac{7}{2} \mathrm{H}_{2} \rightarrow \mathrm{Li}_{2} \mathrm{~B}_{9} \mathrm{H}_{9}$ & -42 \\
$2 \mathrm{LiH}+10 \mathrm{~B}+4 \mathrm{H}_{2} \rightarrow \mathrm{Li}_{2} \mathrm{~B}_{10} \mathrm{H}_{10}$ & -87 \\
$2 \mathrm{LiH}+11 \mathrm{~B}+\frac{9}{2} \mathrm{H}_{2} \rightarrow \mathrm{Li}_{2} \mathrm{~B}_{11} \mathrm{H}_{11}$ & -79 \\
$2 \mathrm{LiH}+12 \mathrm{~B}+5 \mathrm{H}_{2} \rightarrow \mathrm{Li}_{2} \mathrm{~B}_{12} \mathrm{H}_{12}$ & -125 \\
$\mathrm{LiH}+\mathrm{B}+\frac{3}{2} \mathrm{H}_{2} \rightarrow \mathrm{LiBH}_{4}$ & -75 \\
\hline \hline
\end{tabular}

$$
\mathrm{LiBH}_{4} \rightarrow \mathrm{LiBH}+\frac{3}{2} \mathrm{H}_{2} .
$$

We also performed the first-principles calculation of the orthorhombic phase of Pnma LiBH. The reaction enthalpy for Eq. (5) is $1.30 \mathrm{eV}$ per $\mathrm{LiBH}_{4}$ formula unit $\left(84 \mathrm{~kJ} / \mathrm{mol} \mathrm{H}_{2}\right)$, which is in good agreement with the reported value of $1.28 \mathrm{eV}$ per $\mathrm{LiBH}_{4}$ formula unit in Ref. 24. On the other hand, the reaction enthalpy of Eq. (3) is $0.63 \mathrm{eV}$ per $\mathrm{LiBH}_{4}$ formula unit. Therefore, the dehydriding reaction via the intermediate compound $\mathrm{Li}_{2} \mathrm{~B}_{12} \mathrm{H}_{12}$ is the energetically more preferable one.

\section{B. Intermediate compound: $\mathbf{L i}_{2} \mathbf{B}_{12} \mathrm{H}_{12}$}

Here we describe the fundamental properties, such as the crystal structure, the electronic structure, and the $\Gamma$-phonon

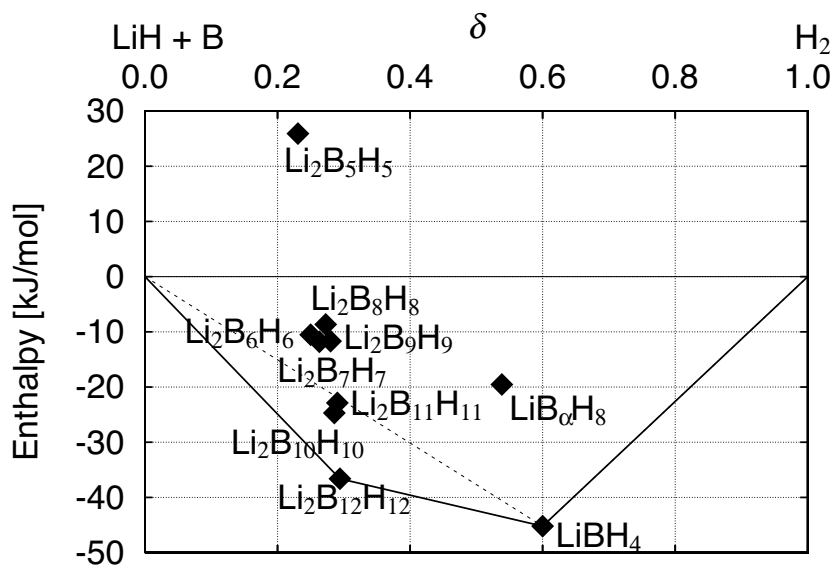

FIG. 1. Enthalpy of the reaction where reactants are $(1-\delta)$ $\times[\mathrm{LiH}+\mathrm{B}]$ and $\delta$ mole of molecular $\mathrm{H}_{2}$. The plotted solid diamonds show the enthalpy of the reaction where the compound $\mathrm{LiB}_{x} \mathrm{H}_{y}$ (and $\left.\mathrm{LiH}\right)$ is produced at $\delta=(y-1) /(2 x+y-1)$ mole fraction of $\mathrm{H}_{2}$ [reaction Eq. (2) in the text]. The solid line corresponds to the enthalpy of the most stable reaction.

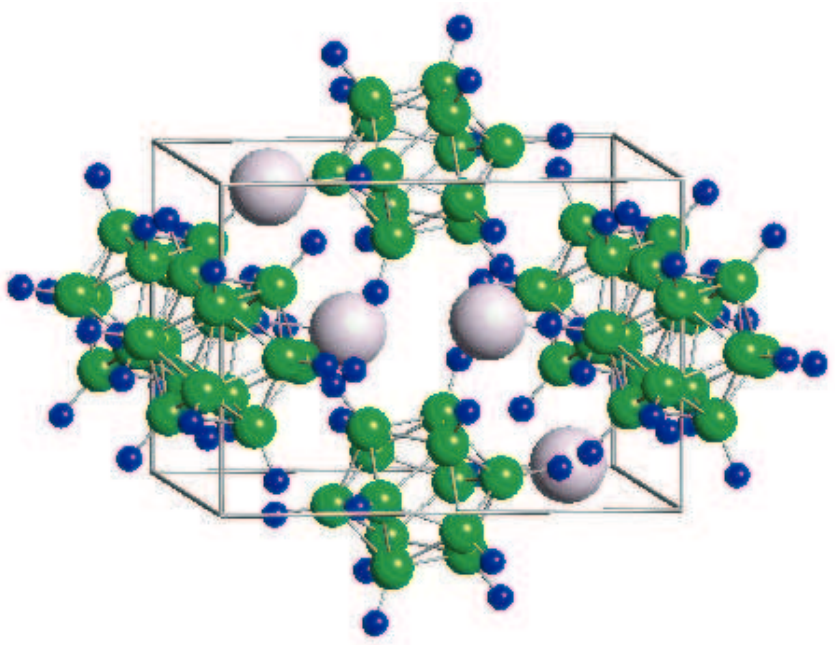

FIG. 2. (Color online) Crystal structure model of monoclinic $\mathrm{Li}_{2} \mathrm{~B}_{12} \mathrm{H}_{12}$ (type 2). Large, middle, and small spheres denote $\mathrm{Li}, \mathrm{B}$, and $\mathrm{H}$ atoms, respectively.

frequencies, on $\mathrm{Li}_{2} \mathrm{~B}_{12} \mathrm{H}_{12}$, which is expected as the intermediate compound of $\mathrm{LiBH}_{4}$.

The optimized crystal-structure model of monoclinic $\mathrm{Li}_{2} \mathrm{~B}_{12} \mathrm{H}_{12}$ is shown in Fig. 2. The bond lengths between a B and $\mathrm{H}$ atom of $\mathrm{Li}_{2} \mathrm{~B}_{12} \mathrm{H}_{12}$ are $1.20-1.21 \AA$, and they are very close to those for $\mathrm{LiBH}_{4}(1.23-1.24 \AA)$ reported in Ref. 2. As for the B-B bond lengths of intra-icosahedron, the values of 1.779-1.811 $\AA$ for $\mathrm{Li}_{2} \mathrm{~B}_{12} \mathrm{H}_{12}$ are comparable to the experimental ones for the $\alpha$-rhombohedral boron $(\alpha$-B) of $1.751-1.806 \AA,{ }^{25}$ too. Since a boron crystal has the icosahedral $\mathrm{B}_{12}$ cluster as a common structural component, the decomposition of a $\left[\mathrm{B}_{12} \mathrm{H}_{12}\right]^{2-}$ anion into a $\mathrm{B}_{12}$ a cluster and hydrogen molecule is easy to understand.

Figure 3 shows the total and partial density of states (DOS) for $\mathrm{Li}_{2} \mathrm{~B}_{12} \mathrm{H}_{12}$, which denotes that it has the energy gap of $5.60 \mathrm{eV}$. Since there is little contribution of the $\mathrm{Li}$ orbital occupied states, $\mathrm{Li}_{2} \mathrm{~B}_{12} \mathrm{H}_{12}$ consists of $\mathrm{Li}^{+}$and $\left[\mathrm{B}_{12} \mathrm{H}_{12}\right]^{2-}$ ions. The orbitals of $\mathrm{B}$ and $\mathrm{H}$ hybridize each other and the feature of occupied states in DOS is analogous with the distribution of the computed energies of the bonding molecular orbitals in $\left[\mathrm{B}_{12} \mathrm{H}_{12}\right]^{2-} .26$

The $\Gamma$-phonon mode frequencies of monoclinic $\mathrm{Li}_{2} \mathrm{~B}_{12} \mathrm{H}_{12}$ have been calculated so that the vibrational properties can be compared with experiments easily and directly. The phonon density of states is shown in Fig. 4. It is divided into three regions in the same case as $\mathrm{LiBH}_{4}$. The first region is less than $300 \mathrm{~cm}^{-1}$, where the displacements of $\mathrm{Li}$ atoms are dominant. The second region is between 450 and $1100 \mathrm{~cm}^{-1}$, where the $\mathrm{B}-\mathrm{H}$ bond of $\left[\mathrm{B}_{12} \mathrm{H}_{12}\right]^{2-}$ dianions vibrates with a change in angle between them (bending modes), and the third region is between 2400 and $2600 \mathrm{~cm}^{-1}$, where the interatomic distance of $\mathrm{B}-\mathrm{H}$ bond is changing along the bond axis (stretching modes). The frequencies of bending modes are lower than $\mathrm{LiBH}_{4}$, described in Ref. 2, while stretching modes are higher.

The investigation using in situ Raman spectroscopy is effective for the confirmation of the short-range order or bonding of $\mathrm{LiBH}_{4} \cdot{ }^{27} \mathrm{We}$ examine the atomistic vibrations of 


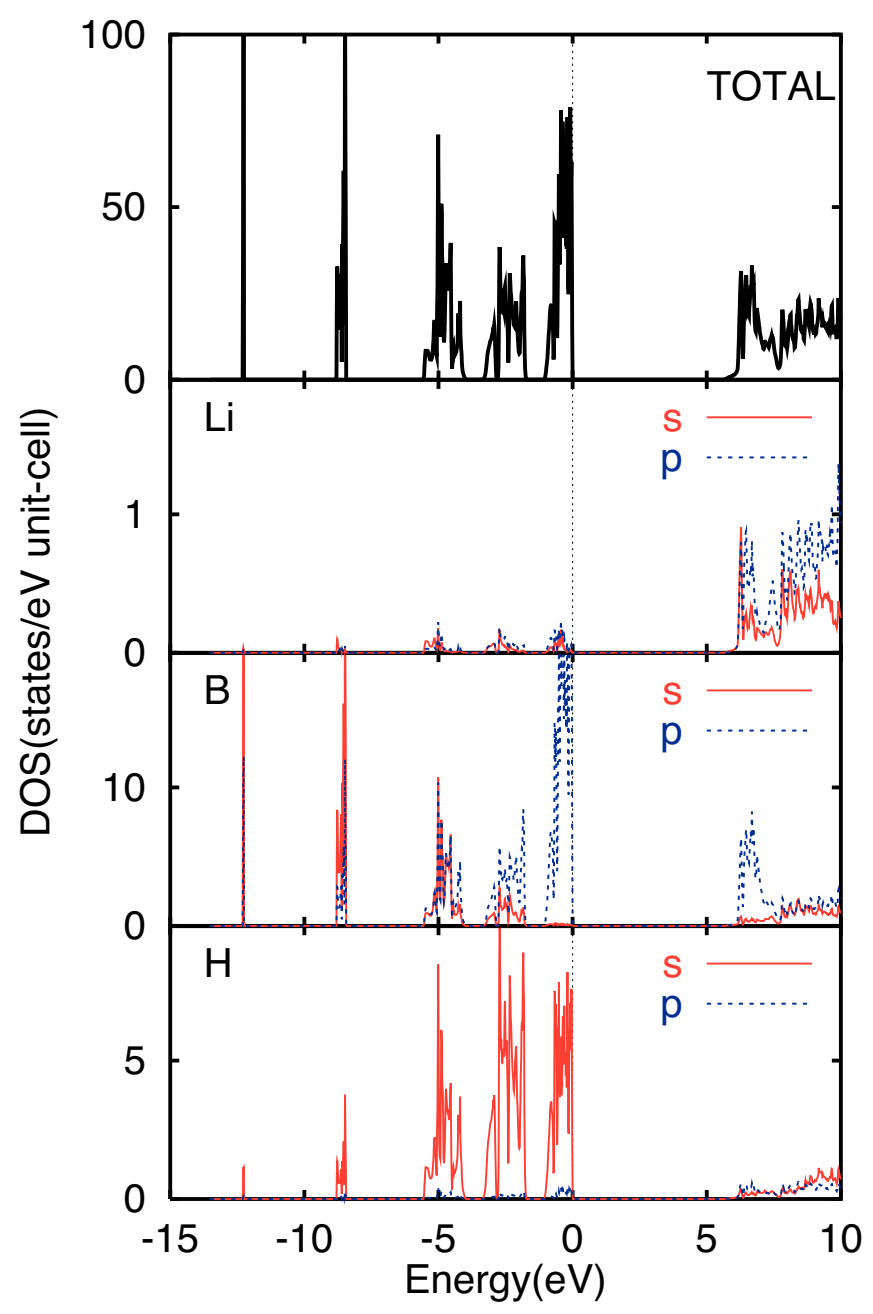

FIG. 3. (Color online) The total and partial DOS for $\mathrm{Li}_{2} \mathrm{~B}_{12} \mathrm{H}_{12}$. The energy is measured in electron-volts relative to the top of valence states.

$\mathrm{LiBH}_{4}$ during heating by in situ Raman spectroscopy, and the identification of spectra modes originating from $\mathrm{Li}_{2} \mathrm{~B}_{12} \mathrm{H}_{12}$ is now in progress. ${ }^{28}$

\section{Stability of complex anions: $\left[\mathrm{B}_{n} \mathrm{H}_{n}\right]^{2-}$}

Finally, we consider the relation between the stability of the compounds $\mathrm{Li}_{2} \mathrm{~B}_{n} \mathrm{H}_{n}$ and those of complex anions $\left[\mathrm{B}_{n} \mathrm{H}_{n}\right]^{2-}$. The energies of the isolated $\left[\mathrm{B}_{n} \mathrm{H}_{n}\right]^{2-}$ are obtained using a face-centered-cubic supercell with $a=20 \AA$. The single $\Gamma$ point is used for the k-point sampling. The energies for the charged systems are computed by adding uniform background charges and improved with Makov and Payne correction $^{29}$ for the interaction between periodic image charges.

Figure 5 shows the comparison of the formation energies, $E_{f}^{\text {solid }}$ and $E_{f}^{\text {complex }}$, corresponding to the following reactions:

$$
2 \mathrm{LiH}+n \mathrm{~B}+\frac{n-2}{2} \mathrm{H}_{2} \leftrightarrow \mathrm{Li}_{2} \mathrm{~B}_{n} \mathrm{H}_{n}
$$

and

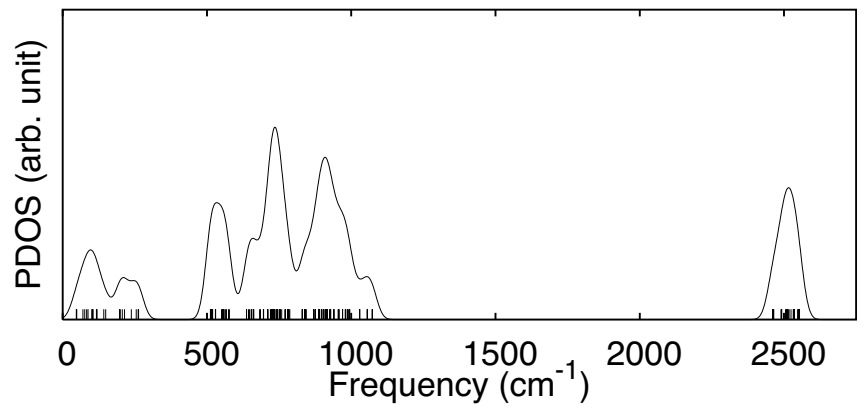

FIG. 4. Phonon DOS for monoclinic $\mathrm{Li}_{2} \mathrm{~B}_{12} \mathrm{H}_{12}$. The contribution of the TO $\Gamma$-phonon modes indicated by vertical bars is only taken into account and the Gaussian broadening with a width of $30 \mathrm{~cm}^{-1}$ is used.

$$
n \mathrm{~B}+\frac{n}{2} \mathrm{H}_{2}+2 e^{-} \leftrightarrow\left[\mathrm{B}_{n} \mathrm{H}_{n}\right]^{2-},
$$

where the energies are normalized by the number of $\mathrm{B}-\mathrm{H}$ pairs for comparison purposes. We can find a fairly good correlation between both energies. This is probably due to the fact that the electrostatic interaction between $\mathrm{Li}^{+}$and $\left[\mathrm{B}_{n} \mathrm{H}_{n}\right]^{2-}$ is not sensitive to $n$ and a large part of this energy cancels out with that of $\mathrm{LiH}$ in Eq. (6). Among the closo-type dianions considered here, $\left[\mathrm{B}_{12} \mathrm{H}_{12}\right]^{2-}$ is the most stable one.

$\mathrm{LiBH}_{4}$ desorbs hydrogen at temperatures above the melting point. The latent heat of fusion has been reported ${ }^{30}$ to be $0.078 \mathrm{eV} /$ formula unit for $\mathrm{LiBH}_{4}$ and similar values are expected for $\mathrm{Li}_{2} \mathrm{~B}_{n} \mathrm{H}_{n}$, which is considerably smaller than the energy difference between $\left[\mathrm{B}_{12} \mathrm{H}_{12}\right]^{2-}$ and other closoe-type dianions. The stability of the $\left[\mathrm{B}_{12} \mathrm{H}_{12}\right]^{2-}$ anion supports our main conclusion in this study, that is, the intermediate phase suggested by the experiment is $\mathrm{Li}_{2} \mathrm{~B}_{12} \mathrm{H}_{12}$.

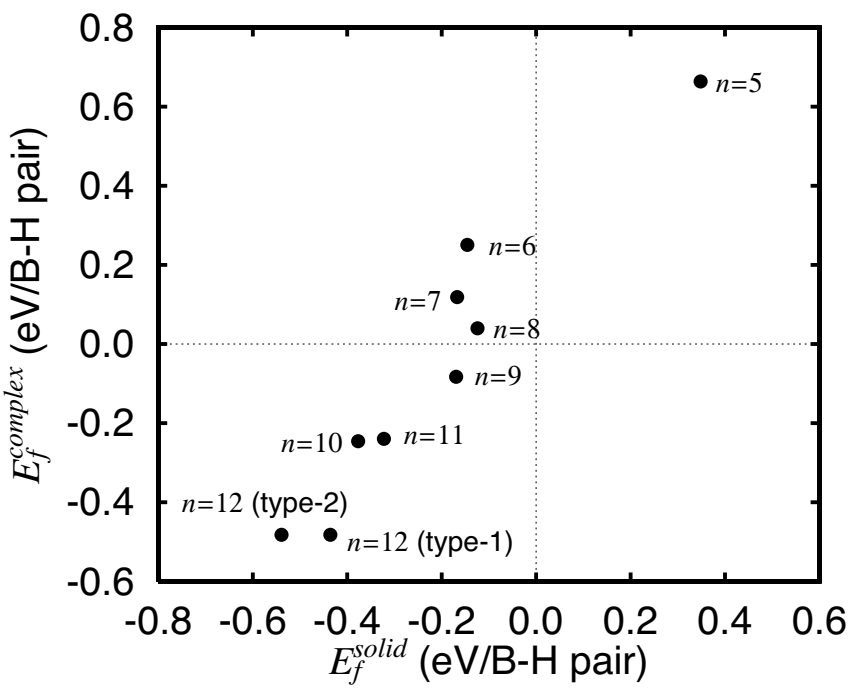

FIG. 5. Comparison of the formation energies, $E_{f}^{\text {solid }}$ and $E_{f}^{\text {complex }}$, corresponding to the reactions Eq. (6) and Eq. (7) in the text, respectively, where the energies are normalized by the number of B-H pairs. 


\section{SUMMARY}

We have examined the stability of $\mathrm{LiB}_{3} \mathrm{H}_{8}$ and $\mathrm{Li}_{2} \mathrm{~B}_{n} \mathrm{H}_{n}(n=5-12)$, which are the possible intermediate compounds of $\mathrm{LiBH}_{4}$, by the first-principles calculation. Our computational results for the enthalpy of the hydriding reactions provide that monoclinic $\mathrm{Li}_{2} \mathrm{~B}_{12} \mathrm{H}_{12}$ is the most stable one among the candidates. The following hydriding (dehydriding) process of $\mathrm{LiBH}_{4}$ is proposed: $\mathrm{LiBH}_{4} \leftrightarrow \frac{1}{12} \mathrm{Li}_{2} \mathrm{~B}_{12} \mathrm{H}_{12}+\frac{5}{6} \mathrm{LiH}+\frac{13}{12} \mathrm{H}_{2} \leftrightarrow \mathrm{LiH}+\mathrm{B}+\frac{3}{2} \mathrm{H}_{2}$. The hydrogen content of the first and the second reaction is 10 and 4 mass $\%$, respectively, which agrees well with the thermal desorption spectra (TDS) experiment on $\mathrm{LiBH}_{4} \cdot{ }^{1}$ The heat of formation without zero-point energy corrections for the first reaction, which is estimated from the solid state $\mathrm{LiBH}_{4}$ with Pnma symmetry (not liquid $\mathrm{LiBH}_{4}$ ), is $56 \mathrm{~kJ} / \mathrm{mol} \mathrm{H}_{2}$. This value is lower than that for the direct reaction $\left(\mathrm{LiBH}_{4} \leftrightarrow \mathrm{LiH}+\mathrm{B}+\frac{3}{2} \mathrm{H}_{2}\right)$. Therefore, the lowtemperature release of hydrogen can be expected by use of this intermediate compound.

We have calculated the electronic structure and the $\Gamma$-phonon frequencies of monoclinic $\mathrm{Li}_{2} \mathrm{~B}_{12} \mathrm{H}_{12}$. This compound has the energy gap of $5.60 \mathrm{eV}$ and consists of $\mathrm{Li}^{+}$and $\left[\mathrm{B}_{12} \mathrm{H}_{12}\right]^{2-}$ ions. From the phonon DOS, it is predicted that its bending modes have lower frequencies than that of $\mathrm{LiBH}_{4},{ }^{2}$ while stretching modes are higher. The identification of the experimental Raman-spectra modes originating from $\mathrm{Li}_{2} \mathrm{~B}_{12} \mathrm{H}_{12}$ is now in progress.
The stability of closo-borane complex anions $\left[\mathrm{B}_{n} \mathrm{H}_{n}\right]^{2-}$ was also examined. We found a fairly good correlation between the formation energies of the solid phases and the isolated dianions. This result supports the validity of the intermediate compound indicated in the TDS experiment being $\mathrm{Li}_{2} \mathrm{~B}_{12} \mathrm{H}_{12}$.

There are various kinds of borane, such as nido-type $\left[\mathrm{B}_{n} \mathrm{H}_{n+4}\right]$ and arachno-type $\left[\mathrm{B}_{n} \mathrm{H}_{n+6}\right]$, in addition to closotype borane $\left[\mathrm{B}_{n} \mathrm{H}_{n+2}\right] .{ }^{31}$ The nido and arachno borane are derived from closo borane by removing one and two vertices, respectively. These generate the salts in the ionized state as well as closo-type dianions. These alkali-metal salts are also the candidates of the intermediate compound of $\mathrm{LiBH}_{4}$. We will study the details of the hydriding (dehydriding) process for $\mathrm{LiBH}_{4}$, including the stability of these materials, in the future.

\section{ACKNOWLEDGMENTS}

We wish to thank M. Matsumoto, R. Jinnouchi, and S. Hyodo for helpful discussions. This work was partially supported by the New Energy and Industrial Technology Development Organization (NEDO), International Joint Research under the "Development for Safe Utilization and Infrastructure of Hydrogen" Project (2004-2005).
${ }^{1}$ A. Züttel, P. Wenger, S. Rentsch, P. Sudan, Ph. Mauron, and Ch. Emmenegger, J. Power Sources 118, 1 (2003).

${ }^{2}$ K. Miwa, N. Ohba, S. I. Towata, Y. Nakamori, and S. I. Orimo, Phys. Rev. B 69, 245120 (2004).

${ }^{3}$ S. Orimo, Y. Nakamori, and A. Züttel, Mater. Sci. Eng., B 108, 51 (2004).

${ }^{4}$ P. Chen, Z. Xiong, J. Luo, J. Lin, and K. L. Tan, Nature (London) 420, 302 (2002).

${ }^{5}$ Y. Nakamori and S. Orimo, Mater. Sci. Eng., B 108, 48 (2004).

${ }^{6}$ K. Miwa, N. Ohba, S. I. Towata, Y. Nakamori, and S. I. Orimo, Phys. Rev. B 71, 195109 (2005).

${ }^{7}$ D. Vanderbilt, Phys. Rev. B 41, R7892 (1990); K. Laasonen, A. Pasquarello, R. Car, C. Lee, and D. Vanderbilt, ibid. 47, 10142 (1993).

${ }^{8}$ P. Hohenberg and W. Kohn, Phys. Rev. 136, B864 (1964); W. Kohn and L. J. Sham, Phys. Rev. 140, A1133 (1965).

${ }^{9}$ J. P. Perdew, K. Burke, and M. Ernzerhof, Phys. Rev. Lett. 77, 3865 (1996); 78, 1396(E) (1997).

${ }^{10}$ D. R. Hamann, M. Schlüter, and C. Chiang, Phys. Rev. Lett. 43, 1494 (1979).

${ }^{11}$ A. M. Rappe, K. M. Rabe, E. Kaxiras, and J. D. Joannopoulos, Phys. Rev. B 41, 1227 (1990).

${ }^{12}$ S. G. Louie, S. Froyen, and M. L. Cohen, Phys. Rev. B 26, 1738 (1982).

${ }^{13}$ A. Fukumoto and K. Miwa, Phys. Rev. B 55, 11155 (1997).

${ }^{14}$ V. Eyret, J. Comput. Phys. 124, 271 (1996).

${ }^{15}$ N. D. Mermin, Phys. Rev. 137, A1441 (1965).

${ }^{16}$ P. E. Blochl, O. Jepsen, and O. K. Andersen, Phys. Rev. B 49, 16223 (1994).

${ }^{17}$ K. Kunc and R. M. Martin, Phys. Rev. Lett. 48, 406 (1982).
${ }^{18}$ H. J. Deiseroth, O. Sommer, H. Binder, K. Wolfer, and B. Frei, Z. Anorg. Allg. Chem. 571, 21 (1989).

${ }^{19}$ I. Y. Kuznetsov, D. M. Vinitskii, K. A. Solntsev, N. T. Kuznetsov, and L. A. Butman, Russ. J. Inorg. Chem. 32, 1803 (1987).

${ }^{20}$ I. Tiritiris and T. Schleid, Z. Anorg. Allg. Chem. 629, 1390 (2003).

${ }^{21}$ T. Peymann, C. B. Knobler, S. I. Khan, and M. F. Hawthorne, J. Am. Chem. Soc. 123, 2182 (2001).

${ }^{22}$ R. D. Dobrott and W. N. Lipscomb, J. Chem. Phys. 37, 1779 (1962).

${ }^{23}$ O. Volkov, W. Dirk, U. Englert, and P. Paetzold, Z. Anorg. Allg. Chem. 625, 1193 (1999).

${ }^{24}$ J. K. Kang, S. Y. Kim, Y. S. Han, R. P. Muller, and W. A. Goddard III, Appl. Phys. Lett. 87, 111904 (2005).

${ }^{25}$ B. Morosin, A. W. Mullendore, D. Emin, and G. A. Slack, in Boron-Rich Solids, edited by D. Emin, T. L. Aselage, C. L. Beckel, I. A. Howard, and C. Wood, AIP Conf. Proc. No. 140 (AIP, New York, 1986), p. 70.

${ }^{26}$ R. B. King, I. Silaghi-Dumitrescu, and A. Lupan, Inorg. Chem. 44, 7819 (2005).

${ }^{27}$ S. Orimo, Y. Nakamori, G. Kitahara, K. Miwa, N. Ohba, S. Towata, and A. Züttel, J. Alloys Compd. 404-406, 427 (2005).

${ }^{28}$ S. Orimo, Y. Nakamori, N. Ohba, K. Miwa, M. Aoki, S. Towata, and A. Züttel, Appl. Phys. Lett. 89, 021920 (2006).

${ }^{29}$ G. Makov and M. C. Payne, Phys. Rev. B 51, 4014 (1995).

${ }^{30}$ M. B. Smith and G. E. Bass, Jr., J. Chem. Eng. Data 8, 342 (1963).

${ }^{31}$ G. A. Olah, K. Wade, and R. E. Williams, Electron Deficient Boron and Carbon Clusters (Wiley, New York, 1991). 